\title{
Poor prognosis of nucleophosmin overexpression in solid tumors: a meta- analysis
}

Siying Chen ${ }^{1 \dagger}$, Hairong He${ }^{2 \dagger}$, Yan Wang ${ }^{1}$, Leichao Liu' ${ }^{1}$ Yang Liu' ${ }^{1}$, Haisheng You', Yalin Dong ${ }^{1 *}$ and Jun Lyu ${ }^{2^{*}}$

\begin{abstract}
Background: Nucleophosmin is a non-ribosomal nucleolar phosphoprotein that is found primarily in the nucleolus region of cell nucleus, plays multiple important roles in tumor processes. Accumulated previous studies have reported a potential value of NPM acted as a biomarker for prognosis in various solid tumors, but the results were more inconsistency. We performed this meta-analysis to precisely evaluate the prognostic significance of NPM in solid tumors.

Methods: Clinical data were collected from a comprehensive literature search in PubMed, Web of Science, Embase, and China National Knowledge Infrastructure databases (up to October, 2017). A total of 11 studied with 997 patients were used to assess the association of NPM expression and patients' overall survival (OS). The hazard ratio (HR) or odds ratio (OR) with its 95\% confidence intervals (Cl) were calculated to estimate the effect.
\end{abstract}

Results: The pooled results indicated that higher expression of NPM was observably correlated with poor OS in solid tumor ( $\mathrm{HR}=1.85,95 \% \mathrm{Cl}: 1.44-2.38, P<0.001)$. Furthermore, high expression of NPM was associated with some phenotypes of tumor aggressiveness, such as tumor stage (4 studies, III/IV vs. I/II, OR=5.21, 95\% Cl: 2.72-9.56, $P<0.001$ ), differentiation grade (poor vs. well/moderate, $\mathrm{OR}=1.82,95 \% \mathrm{Cl}: 1.01-3.27, P=0.046$ ).

Conclusion: This meta-analysis indicated that NPM may act as a valuable prognosis biomarker and a potential therapeutic target in human solid tumors.

Keywords: NPM, Sold tumors, Prognosis, Meta-analysis

\section{Background}

Nucleophosmin (NPM), also known as B23, numatrin or NO38, was originally identified as a nucleolar phosphoprotein [1]. It was abundantly expressed in the granular region of the nucleolus, which could shuttle between the nucleus and cytoplasm during the cell cycle [2]. NPM consists of 294 amino acids [3]. It is highly conserved phosphoprotein and extensively distributed among different species. Its molecular weight is around $37 \mathrm{kDa}$ and isoelectric point (pI) is 5.1 to 5 [4].

NPM is a multifunctional nucleolar phosphoprotein. Previous studies showed that NPM acted as a factor in ribosome biogenesis, which could regulate ribosome

\footnotetext{
* Correspondence: dongyalin@mail.xjtu.edu.cn; lujun2006@xjtu.edu.cn ${ }^{\dagger}$ Siying Chen and Hairong He contributed equally to this work.

'Department of Pharmacy, the First Affiliated Hospital of Xi'an Jiaotong University, No. 277 of Yanta west road, Xi'an 710061, Shaanxi, China ${ }^{2}$ Clinical Research Center, the First Affiliated Hospital of Xi'an Jiaotong University, No. 277 of Yanta west road, Xi'an 710061, Shaanxi, China
}

assembly and transport ribosomal proteins to the cytoplasm [5]. Additionally, it was proposed that NPM possessed molecular chaperone activities, such as preventing protein aggregation, preserving enzymes activities during thermal denaturation of several different proteins and facilitating renaturation of chemically-denatured proteins [6]. Recently, several studies suggested that NPM played a crucial role in cell growth, proliferation and transformation. It could regulate cell cycle progression and centrosome duplication $[7,8]$. NPM was able to regulate the activity and stability of crucial tumor suppressors such as p53 and ARF [9]. NPM also participated in transcription activation by interacting with transcription factors NF- $\mathrm{kB}$ and c-Myc [10, 11].

In addition, numerous studies displayed NPM could be involved in tumorgenesis. Although NPM is frequently mutated in acute myeloid leukemias [12], it is higher expression in many types of human solid tumors, 
and it has been proposed as a marker for colon, liver, stomach, ovary, thyroid and prostate carcinoma [3, 13-17]. In some cases, because NPM binds to linker histone H1.5, enforced expression of NPM could suppress apoptosis in H1.5 depleted glioma cells, it suggested that effectiveness of targeting NPM could be a potential treatment for glioblastoma [18]. Overexpression of NPM may intensively influence the effects of estrogen on the malignant progression of endometrioid adenocarcinoma via $\mathrm{ER} \alpha$ signaling $[19,20]$. On the contrary, knockout of NPM in cells and mice disturbed the genomic stability, which it contributed to growth-suppressing pathways through the interaction between NPM and ARF. So the loss of NPM expression could contribute to tumorigenesis [9].

Although NPM has a great diversity of biological functions, its physiological function in tumorigenesis is still a controversial issue on account of tumor suppressive and oncogenic functions of NPM. Due to the inconsistency of NPM functions, we preformed this meta-analysis to evaluate the prognostic value of NPM in patients with solid tumors. It expected NPM could serve as a novel biomarker for diagnosis and treatment in solid tumors.

\section{Methods}

\section{Literature search and study selection}

A comprehensive literature search was conducted by using the electronic databases PubMed, Web of Science, Embase, and China National Knowledge Infrastructure databases (up to October, 2017) with the following terms: "nucleophosmin or NPM or B23 or numatrin or NO38 or NPM1" and "cancer or tumor or carcinoma or malignancy or neoplasm" and "prognosis or prognostic or survival or mortality or outcome". The results were restricted to human studies. We also searched the reference lists of the reviews on related topics to identify additional studies.

We diligently screened the eligible studies with the following inclusion criteria: (1) studies assessing the association of NPM expression and prognostic outcomes in solid tumors; (2) NPM expression has been measured in tumor tissue by immunohistochemistry (IHC) stain; (3) dividing NPM expression into "high" and "low" or "positive" and "negative"; (4) offering hazard ratios (HRs) with 95\% confidence intervals (CIs) or sufficient information for estimating these statistics; (5) studies were written as full papers. We excluded the following studies: letters, reviews, abstracts, editorials, case reports, expert opinions, or animal experiments.

\section{Data extraction and quality assessment}

All data included in this meta-analysis were reviewed and extracted independently by two investigators using a predefined form. The collected data included the first author name, publication year, study region, cancer type, number of patients, age, sex, cancer stage or grade, percentage of high NPM expression and the cutoff value, median follow-up months, HR and 95\%CI of high NPM expression group versus low group. For studies that showed only Kaplan-Meier curves, we extracted the survival data by Engauge Digitizer (version 4.1). And the estimated $\mathrm{HR}$ and $95 \% \mathrm{CI}$ were calculated using Tierney's method [21].

The quality of each included study was carefully assessed by two independent authors using NewcastleOttawa Quality Assessment Scale (NOS) [22]. Three evaluation contents contained selection, comparability, and outcome of interest. The studies with higher than 6 scores were considered as high-quality studies.

\section{Statistical analysis}

Statistical analyses were performed using STATA 14.0 software (Stata Corporation, College Station, TX, USA). The pooled HRs and $95 \%$ CIs were used to evaluate the relationship between NPM expression and patients' overall survival (OS). Additionally, odds ratios (ORs) and their 95\%CIs were used to assess the association between NPM expression and the clinicopathological features of solid tumors. The statistical heterogeneity was measured using the Cochran's Q-test and I-squared test [23]. $\mathrm{I}^{2}>50 \%$ or $P<0.10$ were considered as significant heterogeneity. Publication bias was assessed using Begg's funnel plot, the symmetry of funnel plot was evaluated by Egger's test $(P<0.05$ was considered as statistically significance) [24]. The sensitivity analysis was carried out by sequentially removing each study to evaluate the

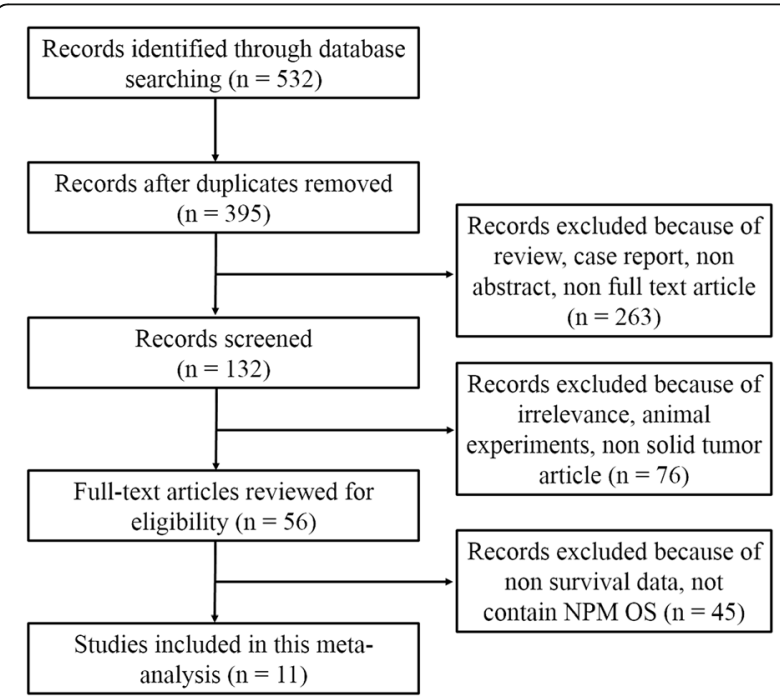

Fig. 1 Flow diagram of the study selection process. NPM: nucleophosmin; OS: overall survival 


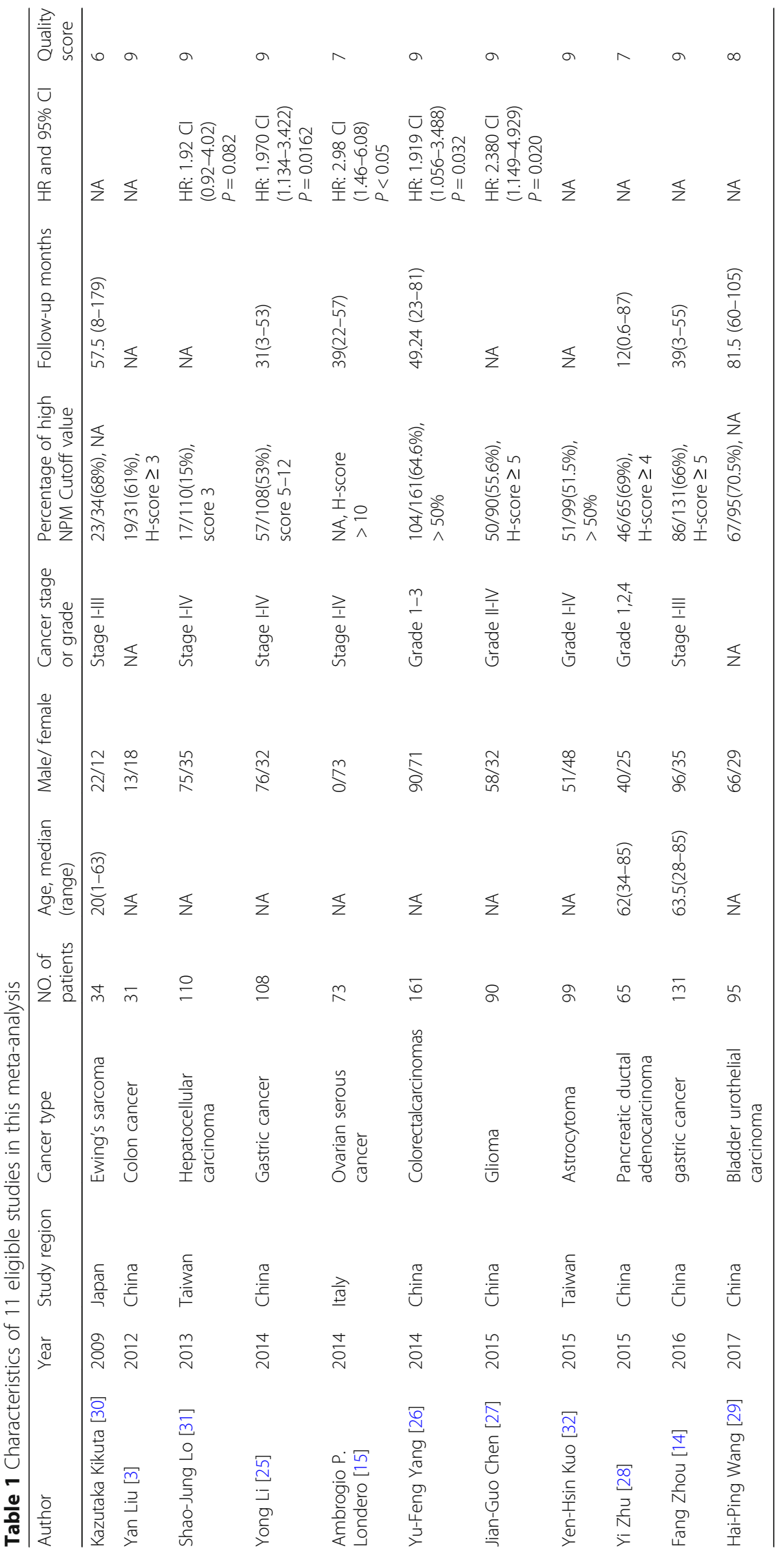


influence of single study on the pooled outcomes. All analysis were calculated using the random-effects model.

\section{Results}

\section{Description of eligible studies}

Initially, a total of 532 studies were identified by electronic search in primary databases. Then 11 eligible studies were included in the final meta-analysis according to the inclusion and exclusion criteria. The concise process of literature selection was presented in Fig. 1.

All 11 studies with a total of 997 patients were used immunohistochemistry method to detect the expression of NPM. The patients from China [3, 14, 25-29], Japan [30], Taiwan [31, 32], Italy [15] were diagnosed with various tumors, including colon cancer, Ewing's sarcoma, hepatocellular carcinoma, gastric cancer, ovarian serous cancer, colorectal carcinomas, glioma, astrocytoma, pancreatic ductal adenocarcinoma, bladder urothelial carcinoma. The main characteristics of these included studies are shown in Table 1 . Of the 11 included studies, the median follow-up time ranged from 0.6 to 179 months, even 4 studies did not report it [3, 27, 31, 32]. One study [15] did not state the percentage of high NPM expression, and the cutoff value for defining positive or high NPM expression could be extracted from 9 studies. The HR and 95\%CI for assessing the association of NPM expression and overall survival were directly reported in 5 studies, and those of other studies only showed Kaplan-Meier survival curves [3, 14, 28-30, 32]. All of included studies were high quality, and they got a score $\geq 6$ NOS assessment.

\section{The prognostic value of NPM in solid tumor patients' overall survival}

All 11 studies were included in this meta-analysis of solid tumor patients' overall survival. A random-effects model was used to calculate the pooled HR and 95\% CI. The result demonstrated that the solid tumor patients with higher expression of NPM had poor prognosis (HR $=1.85$; 95\%CI: $1.44-2.38 ; P<0.001)$. The heterogeneity test showed $P$ value was 0.665 and $\mathrm{I}^{2}$ value was $0.0 \%$ (Fig. 2).

\section{Association of NPM and clinicopathological features}

To explore the role of NPM expression in different solid tumors, we also investigated the correlation between NPM levels and clinicopathological features. The results illustrated in Table 2, NPM expression was not related with solid tumors patients' age, gender and tumor size. However, positive or high expression of NPM was significantly associated with advanced tumor stage (4 studies; III/IV vs. I/II; pooled $\mathrm{OR}=5.21$; $95 \%$ CI: $2.72-9.96 ; P<0.001$; random effects) and advanced differentiation grade (3 studies; poor vs. well $/$ moderate; pooled $\mathrm{OR}=1.82$; $95 \% \mathrm{CI}$ : $1.01-3.27 \mathrm{P}=$ 0.046; random effects) (Figs. 3 and 4).

\section{Sensitivity analysis}

Sensitivity analysis was preformed to assess the potential heterogeneity of each study on the patients' overall survival. The results suggested that the pooled HRs was not influenced the combined results after removing any individual study (Fig. 5). This indicated that the results of meta-analysis were stable and reliable.

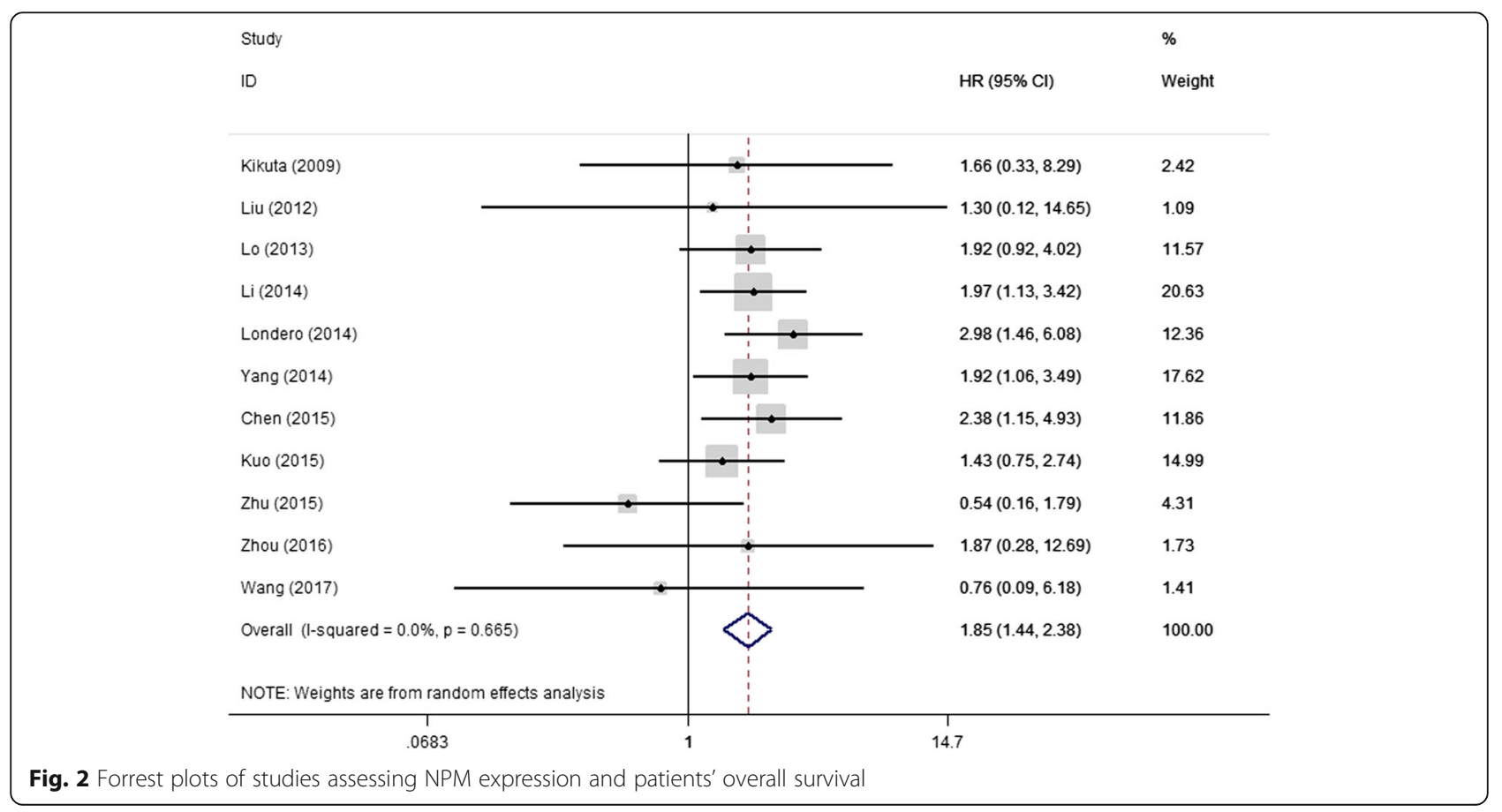


Table 2 Meta-analysis of NPM expression and clinicopathological features in solid tumors

\begin{tabular}{llllll}
\hline Categories & Studies & Pooled OR & $95 \% \mathrm{Cl}$ & Heterogeneity $\mathrm{I}^{2}(\%)$ & $P$ Value \\
\hline Age $(\geq 60$ vs. $<60)$ & 6 & 0.755 & $0.403-1.416$ & 52.1 & 0.381 \\
Gender (male vs. female) & 9 & 0.741 & $0.550-1.000$ & 0.0 & 0.050 \\
Tumor size $(\geq 4$ cm vs. $<4$ cm) & 3 & 0.771 & $0.438-1.358$ & 0.0 & 0.368 \\
Tumor stage (III/IV vs. I/I) & 4 & 5.209 & $2.724-9.959$ & 22.2 & $<0.001$ \\
Differentiation grade (poor vs. well/moderate) & 4 & 1.817 & $1.010-3.266$ & 0.0 & 0.046 \\
\hline
\end{tabular}

\section{Publication bias}

As shown in Fig. 6, the shape of the funnel plot for OS was symmetrical, and the results from Begg's test $(P=$ $0.119)$ and Egger's test $(P=0.191)$ also revealed that there was no obvious publication bias in this meta-analysis.

\section{Discussion}

As a multifunctional factor, NPM participated in cell growth, proliferation, transformation and apoptosis [9, 33]. In the past studies, most of researchers found that overexpression of NPM may promote tumors progression and predict poor prognosis of cancer patients, and they even expected NPM as a new biomolecular marker for improving clinical cancer therapy and outcomes [4, $32,34]$. However, the prognostic value of NPM among different solid tumors is still in contradiction. By summarizing the findings of published literatures, we conducted this comprehensive meta-analysis to assess the association between expression of NPM and the prognosis of solid tumor patients.

This meta-analysis included 11 studies with 997 patients, and the systematically evaluated outcomes demonstrated the high level of NPM was significantly correlated to poor overall survival in various solid tumors. It suggested that NPM overexpression was a potential independent predictor of poor prognosis in most solid tumors, including Ewing's sarcoma, hepatocellular carcinoma, gastric cancer, ovarian serous cancer, colorectal carcinomas, glioma, astrocytoma, pancreatic adenocarcinoma and bladder carcinoma. Moreover, sensitivity analysis reinforced the reliability of this meta-analysis outcomes. And the publication bias was not detected in the pooled outcomes. Although four studies didn't report the median follow-up time, we estimated the outcomes by Kaplan-Meier curves of overall survival, and they didn't impact the stability and reliability of meta-analysis. Besides, according to the subgroup analyses, we also investigated the association between NPM expression and clinicopathological features. The results indicated that the high expression of NPM was obviously related to advanced tumor stage and advanced differentiation grade, which suggested that NPM level probably involved in tumor progression and then affected tumor patients' overall survival.

It has been demonstrated that abnormal expression of NPM could promote tumorigenesis and tumor progression in more different cancers. For instance, as a critical

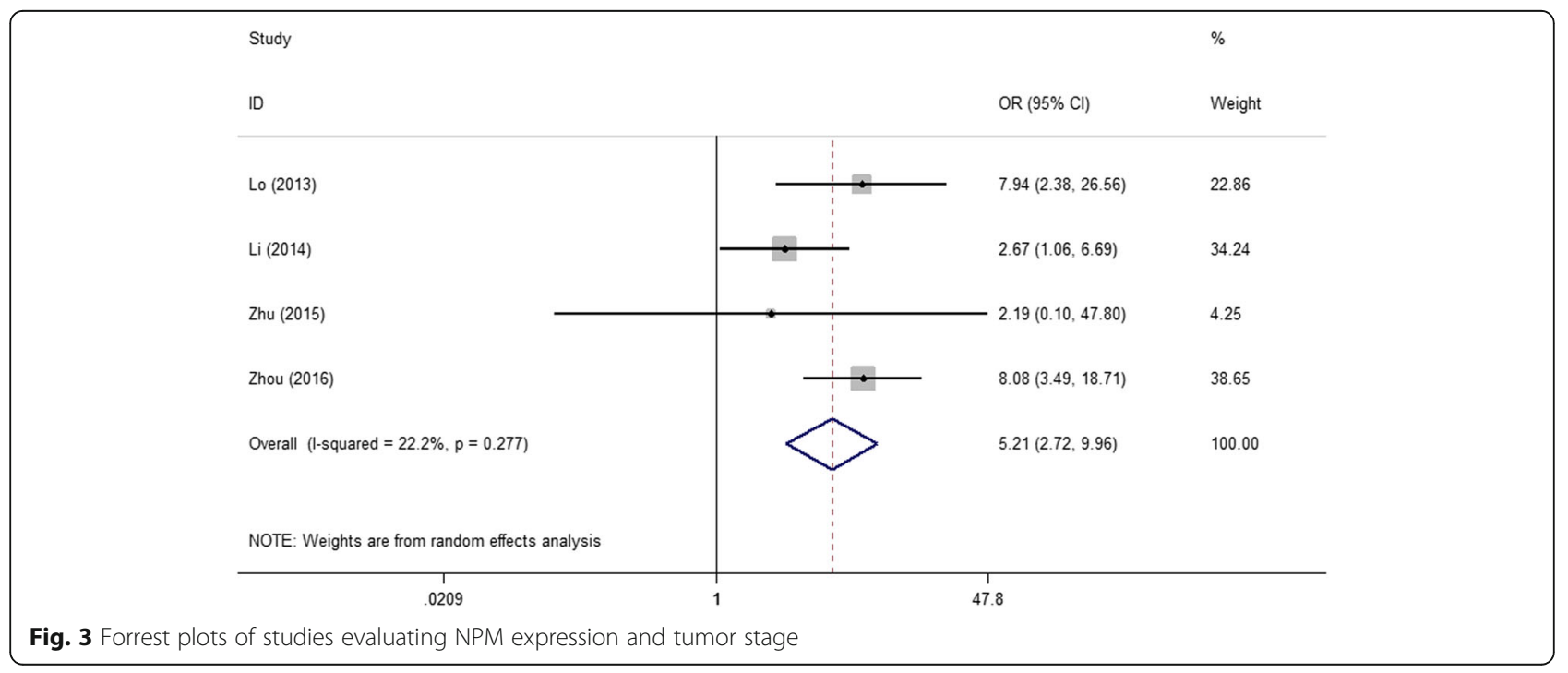




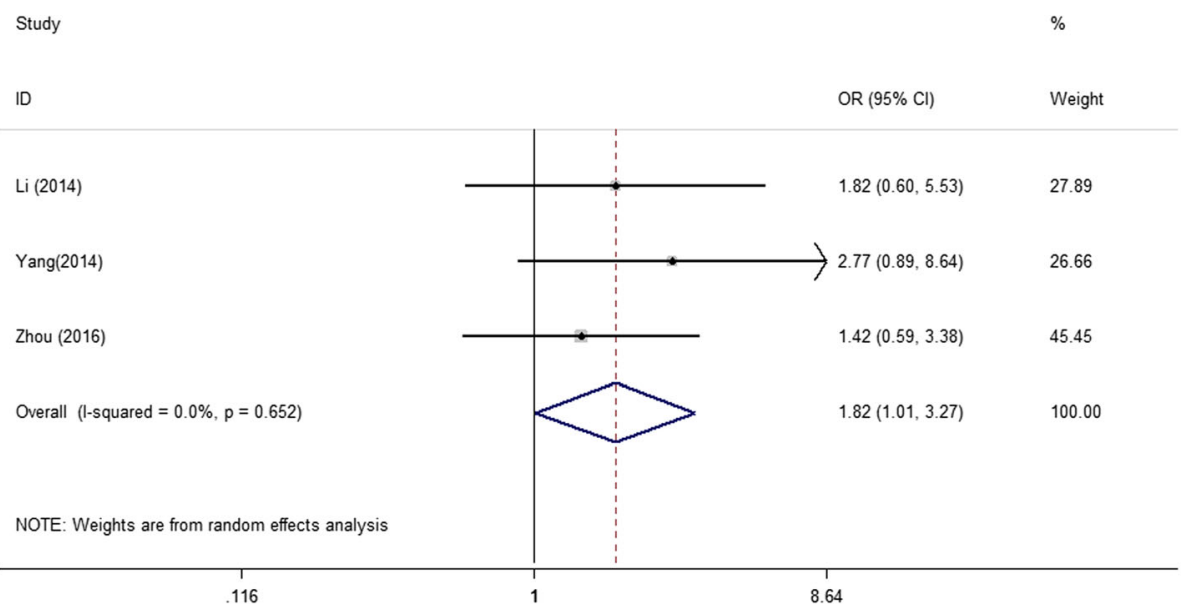

Fig. 4 Forrest plots of studies evaluating NPM expression and differentiation grade

regulator, NPM was overexpressed in prostate cancer, and it regulated cell proliferation [35]. The high expression of NPM is associated with local recurrence, and NPM might be used as a prognostic indicator in oral squamous cell carcinoma [36]. Moreover, NPM was overexpression in thyroid tumors, its dysregulation occurred at protein level and related to an increase of p-Akt level of transformed thyrocytes [16]. NPM might be a useful immunohistochemical marker for differential diagnosis between oncocytoma and chromophobe renal cell carcinomas (RCCs), and increased nucleolar NPM expression in RCCs appeared to be associated with tumor progression [37]. All these researches proved the significant value of NPM as a biomarker in the occurrence and progress of solid tumors. While the mechanism of NPM overexpression should still be further explored and investigated.

To our knowledge, several limitations may exist in our meta-analysis. Firstly, some of the studies did not report the HRs about NPM expression and OS, we only calculated them through Kaplan-Meier survival curves or univariate analysis. These may be less reliable than the accurate HRs directly obtained from published articles [38]. Secondly, the methods and cut-off values for assessing NPM expression and defining NPM positivity or high level were inconsistent. This may lead to heterogeneity. Thirdly, due to the limited number of studies, we were not able to conduct detail subgroup analyses to avoid the tumor heterogeneity. Fourthly, the follow-up period in all included studies were considerably different

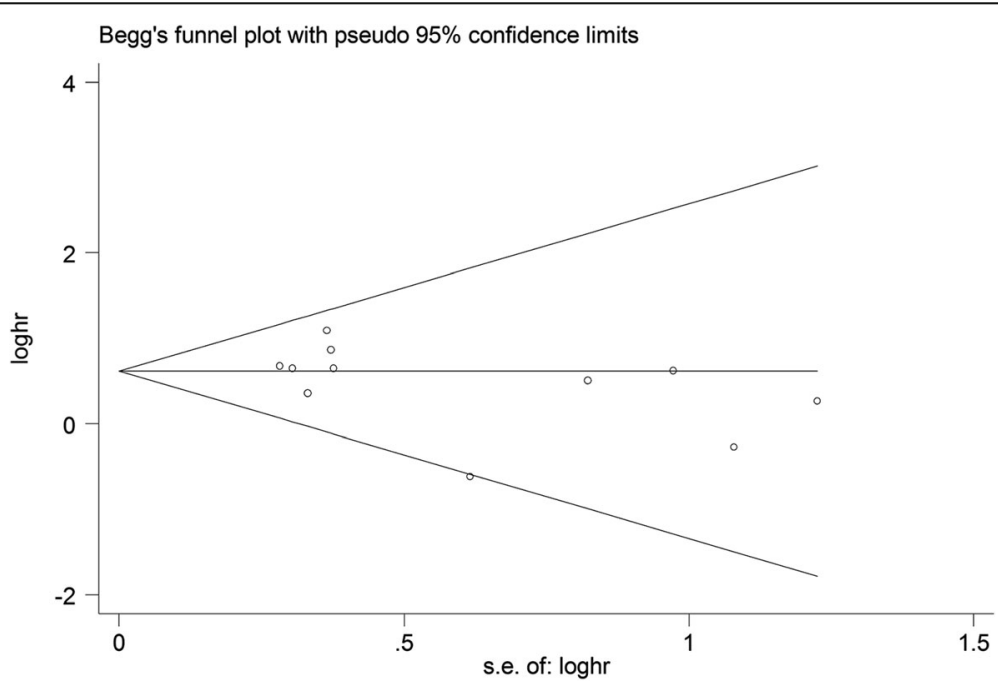

Fig. 5 Sensitivity analysis of the meta-analysis 


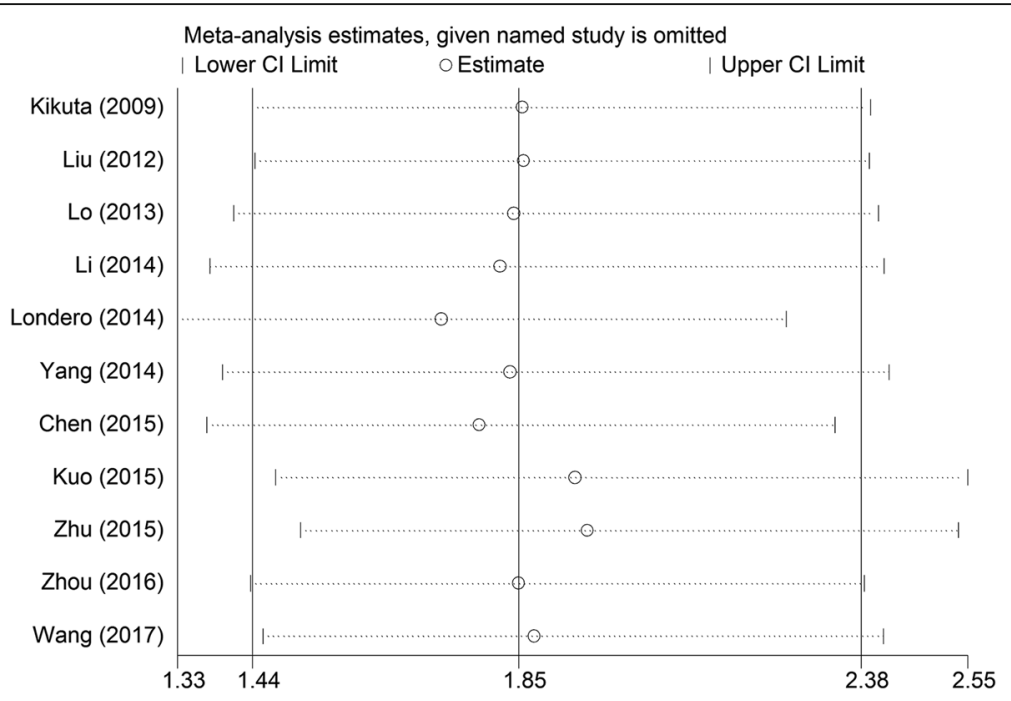

Fig. 6 Begg's funnel plot for potential publication bias of the included literatures

and some of them did not report it. In consequence, the further studies should need to explore the influence of these confounding factors on the pooled results.

\section{Conclusions}

This present study is the first and comprehensive meta-analysis that illustrates the possible prognostic role of NPM up-regulation in solid tumors. Our results suggest that NPM may be a useful prognostic biomarker, and targeting NPM might be a promising therapeutic approach for solid tumors. But further data are still required for the potential effect of NPM on the different solid tumors from future researches.

\section{Abbreviations}

Cl: confidence intervals; HR: Hazard ratio; IHC: immunohistochemistry; NOS: Newcastle-Ottawa Quality Assessment Scale; NPM: Nucleophosmin; OR: Odds ratio; OS: Overall survival

\section{Funding}

This work was supported by the National Natural Science Foundation of China (No. 81502616), the National Social Science Foundation of China (No.16BGL183), and the Natural Science Foundation of Shaanxi Province (No. $2017 \mathrm{JM} 8013$ and No. 2015JM8415).

\section{Availability of data and materials}

All data generated or analysed during this study are included in this published article.

\section{Authors' contributions}

SYC and HRH contributed equally to this work and wrote this manuscript. YW, $L C L, Y L$ and HSY participated in the collection and analysis of data. SYC and HRH performed the statistical analyses. YLD and $J \mathrm{~L}$ conceived the study and designed the manuscript. All authors have read and approved the final manuscript.

\section{Ethics approval and consent to participate}

Not applicable.

\section{Consent for publication}

Not applicable.

\section{Competing interests}

The authors declare that they have no competing interests.

\section{Publisher's Note}

Springer Nature remains neutral with regard to jurisdictional claims in published maps and institutional affiliations.

Received: 29 December 2017 Accepted: 2 August 2018

Published online: 20 August 2018

\section{References}

1. Yung BYM, Chan PK. Identification and characterization of a Hexameric form of Nucleolar Phosphoprotein B23. Biochim Biophys Acta. 1987;925(1):74-82.

2. Borer RA, Lehner CF, Eppenberger HM, Nigg EA. Major nucleolar proteins shuttle between nucleus and cytoplasm. Cell. 1989;56(3):379-90.

3. Liu Y, Zhang F, Zhang XF, Qi LS, Yang L, Guo H, Zhang N. Expression of nucleophosmin/NPM1 correlates with migration and invasiveness of colon cancer cells. J Biomed Sci. 2012:19:53.

4. Lim MJ, Wang XW. Nucleophosmin and human cancer. Cancer Detect Prev. 2006;30(6):481-90.

5. Mitrea DM, Grace CR, Buljan M, Yun MK, Pytel NJ, Satumba J, Nourse A, Park CG, Madan Babu M, White SW, et al. Structural polymorphism in the Nterminal oligomerization domain of NPM1. Proc Natl Acad Sci U S A. 2014; 111(12):4466-71.

6. Szebeni A, Olson MO. Nucleolar protein B23 has molecular chaperone activities. Protein Sci. 1999:8(4):905-12.

7. Okuda M, Horn HF, Tarapore P, Tokuyama Y, Smulian AG, Chan PK, Knudsen ES, Hofmann IA, Snyder JD, Bove KE, et al. Nucleophosmin/B23 is a target of CDK2/cyclin E in centrosome duplication. Cell. 2000:103(1):127-40.

8. Okuda M. The role of nucleophosmin in centrosome duplication. Oncogene. 2002;21(40):6170-4.

9. Grisendi S, Mecucci C, Falini B, Pandolfi PP. Nucleophosmin and cancer. Nat Rev Cancer. 2006:6(7):493-505.

10. Li Z, Boone D, Hann SR. Nucleophosmin interacts directly with c-Myc and controls c-Myc-induced hyperproliferation and transformation. Proc Natl Acad Sci U S A. 2008;105(48):18794-9.

11. Lin J, Kato M, Nagata K, Okuwaki M. Efficient DNA binding of NF-kappaB requires the chaperone-like function of NPM1. Nucleic Acids Res. 2017;45(7): 3707-23.

12. Falini B, Nicoletti I, Martelli MF, Mecucci C. Acute myeloid leukemia carrying cytoplasmic/mutated nucleophosmin (NPMC+ AML): biologic and clinical features. Blood. 2007:109(3):874-85.

13. Xu DH, Liu F, Li X, Chen XF, Jing GJ, Wu FY, Shi SL, Li QF. Regulatory role of nucleophosmin during the differentiation of human liver cancer cells. Int J Oncol. 2014;45(1):264-72. 
14. Zhou F, Chen E, You D, Song Y, Sun Z, Yue L. Both high expression of nucleophosmin/B23 and CRM1 predicts poorer prognosis in human gastric cancer. APMIS. 2016;124(12):1046-53.

15. Londero AP, Orsaria M, Tell G, Marzinotto S, Capodicasa V, Poletto M, Vascotto C, Sacco C, Mariuzzi L. Expression and prognostic significance of APE1/Ref-1 and NPM1 proteins in high-grade ovarian serous cancer. Am J Clin Pathol. 2014;141(3):404-14.

16. Pianta A, Puppin C, Franzoni A, Fabbro D, Di Loreto C, Bulotta S, Deganuto M, Paron I, Tell G, Puxeddu E, et al. Nucleophosmin is overexpressed in thyroid tumors. Biochem Biophys Res Commun. 2010; 397(3):499-504

17. Bocker T, Bittinger A, Wieland W, Buettner R, Fauser G, Hofstaedter F, Ruschoff J. In vitro and ex vivo expression of nucleolar proteins B23 and p120 in benign and malignant epithelial lesions of the prostate. Mod Pathol. 1995:8(3):226-31.

18. Holmberg Olausson K, Elsir T, Moazemi Goudarzi K, Nister M, Lindstrom MS. NPM1 histone chaperone is upregulated in glioblastoma to promote cell survival and maintain nucleolar shape. Sci Rep. 2015;5:16495.

19. Zhou Y, Shen J, Xia L, Wang Y. Estrogen mediated expression of nucleophosmin 1 in human endometrial carcinoma clinical stages through estrogen receptor-alpha signaling. Cancer Cell Int. 2014;14(1):540.

20. Chao A, Lin CY, Tsai CL, Hsueh S, Lin YY, Lin CT, Chou HH, Wang TH, Lai CH, Wang HS. Estrogen stimulates the proliferation of human endometrial cancer cells by stabilizing nucleophosmin/B23 (NPM/B23). J Mol Med (Berl). 2013;91(2):249-59.

21. Williamson PR, Smith CT, Hutton JL, Marson AG. Aggregate data metaanalysis with time-to-event outcomes. Stat Med. 2002;21(22):3337-51.

22. Stang A. Critical evaluation of the Newcastle-Ottawa scale for the assessment of the quality of nonrandomized studies in meta-analyses. Eur J Epidemiol. 2010;25(9):603-5.

23. Higgins JP, Thompson SG, Deeks JJ, Altman DG. Measuring inconsistency in meta-analyses. BMJ. 2003;327(7414):557-60.

24. Egger M, Davey Smith G, Schneider M, Minder C. Bias in meta-analysis detected by a simple, graphical test. BMJ. 1997;315(7109):629-34.

25. Li Y, Sun Z, Liu K, Qiu W, Yao R, Feng T, Xin C, Yue L. Prognostic significance of the co-expression of nucleophosmin and trefoil factor 3 in postoperative gastric cancer patients. Mol Clin Oncol. 2014;2(6):1055-61.

26. Yang YF, Zhang XY, Yang M, He ZH, Peng NF, Xie SR, Xie YF. Prognostic role of nucleophosmin in colorectal carcinomas. Asian Pac J Cancer Prev. 2014; 15(5):2021-6.

27. Chen J, Sun J, Yang L, Yan Y, Shi W, Shi J, Huang Q, Chen J, Lan Q. Upregulation of B23 promotes tumor cell proliferation and predicts poor prognosis in glioma. Biochem Biophys Res Commun. 2015;466(1): 124-30.

28. Zhu Y, Shi M, Chen H, Gu J, Zhang J, Shen B, Deng X, Xie J, Zhan X, Peng C. NPM1 activates metabolic changes by inhibiting FBP1 while promoting the tumorigenicity of pancreatic cancer cells. Oncotarget. 2015;6(25):21443-51

29. Wang H, Yuan G, Zhao B, Zhao Y, Qiu Y. High expression of B23 is associated with tumorigenesis and poor prognosis in bladder urothelial carcinoma. Mol Med Rep. 2017;15(2):743-9.

30. Kikuta K, Tochigi N, Shimoda T, Yabe H, Morioka H, Toyama Y, Hosono A, Beppu Y, Kawai A, Hirohashi S, et al. Nucleophosmin as a candidate prognostic biomarker of Ewing's sarcoma revealed by proteomics. Clin Cancer Res. 2009:15(8):2885-94.

31. Lo SJ, Fan LC, Tsai YF, Lin KY, Huang HL, Wang TH, Liu H, Chen TC, Huang SF, Chang CJ, et al. A novel interaction of nucleophosmin with BCL2associated $X$ protein regulating death evasion and drug sensitivity in human hepatoma cells. Hepatology. 2013;57(5):1893-905.

32. Kuo YH, Chen YT, Tsai HP, Chai CY, Kwan AL. Nucleophosmin overexpression is associated with poor survival in astrocytoma. APMIS. 2015; 123(6):515-22

33. Yung BY. Oncogenic role of nucleophosmin/B23. Chang Gung Med J. 2007; 30(4):285-93

34. Di Matteo A, Franceschini M, Chiarella S, Rocchio S, Travaglini-Allocatelli C, Federici L. Molecules that target nucleophosmin for cancer treatment: an update. Oncotarget. 2016;7(28):44821-40.

35. Nigwekar P, Wu C, Yao JL, Bourne PA, Li J, Zhuang Z, Agnese PAD, Walters DC, Huang J. Nucleophosmin, a critical regulator of cell proliferation, is overexpressed in prostate cancer. Modern Pathology. 2007;20:166a-7a.
36. Coutinho-Camillo CM, Lourenco SV, Nishimoto IN, Kowalski LP, Soares FA. Nucleophosmin, p53, and Ki-67 expression patterns on an oral squamous cell carcinoma tissue microarray. Hum Pathol. 2010;41(8):1079-86.

37. Sari A, Calli A, Altinboga AA, Pehlivan FS, Gorgel SN, Balci U, Ermete M, Dincel C, Cakalagaoglu F. Nucleophosmin expression in renal cell carcinoma and oncocytoma. APMIS. 2012;120(3):187-94.

38. Tierney JF, Stewart LA, Ghersi D, Burdett S, Sydes MR. Practical methods for incorporating summary time-to-event data into meta-analysis. Trials. 2007:8:16.

\section{Ready to submit your research? Choose BMC and benefit from:}

- fast, convenient online submission

- thorough peer review by experienced researchers in your field

- rapid publication on acceptance

- support for research data, including large and complex data types

- gold Open Access which fosters wider collaboration and increased citations

- maximum visibility for your research: over $100 \mathrm{M}$ website views per year

At $\mathrm{BMC}$, research is always in progress.

Learn more biomedcentral.com/submissions 